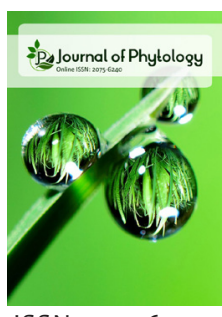

ISSN: $2075-6240$

\title{
Synergistic effects of Ruta montana (Clus.) L. essential oil and antibiotics against some pathogenic bacteria
}

\author{
Azzeddine Zeraib ${ }^{\mathrm{a}, \mathrm{b} *}$, Lamia Boudjedjouc, Naziha Suicic, Tarek Benmeddour ${ }^{\mathrm{b}, \mathrm{c}}$, \\ Khaled Rahal ${ }^{\mathrm{a}}$, Azzedine Fercha ${ }^{\mathrm{a}}$ \\ aUniversity of Abbes Laghrour, Faculty of Nature and Life Sciences, Department of Agronomy, Khenchela, Algeria \\ bUniversity of Biskra, Laboratory of Genetics, biotechnology and valorization of bio-resources, Biskra, Algeria \\ 'University of Biskra, Faculty of Exact Sciences and Nature and Life Sciences, Department of Nature and Life \\ Sciences, Biskra, Algeria
}

\begin{abstract}
Antibiotic resistance has been called one of the world's most pressing public health threats. The combination of essential oils with conventional antibiotics is one of the emerging approaches that could help prevent this problem. In light of this, the present study aimed to investigate the impact of the combination of Ruta montana essential oil with conventional antibiotics on some pathogenic bacteria. The essential oil isolated by hydrodistillation was first analyzed using GC-MS then tested alone and in combination with five recommended antibiotics against three bacterial strains by the agar disc diffusion and broth micro-dilution methods. Out of forty-nine peaks, thirty-eight components were identified representing $98.17 \%$ of the total oil composition. The major components were 2-Undecanone (63.39\%), 2-Nonanone (5.65\%), 2-Acetoxytetradecane (4.94\%), 2-Decanone (4.47\%) and 2-Dodecanone (3.35\%). While R. montana essential oil showed only weak antibacterial activity compared to the antibiotics tested alone, unexpectedly, the combination of RM essential oil with antibiotics remarkably increased the antibacterial activity of the antibiotics through synergistic effects in up to $70 \%$ of cases. These results suggest that combining antibiotics with essential oils, even those with low antibacterial activity, may be effective in overcoming problems caused by increasing bacterial resistance.
\end{abstract}

*Corresponding author:

Azzeddine Zeraib,

Email: azzeraib@yahoo.fr; zeraib.

azzeddine@univ-khenchela.dz_Keywords: Essential oil, Ruta montana, GC-MS, Combination, Antibiotic, Synergy.

\section{INTRODUCTION}

The increased prevalence of bacterial resistance is one of the major problems of global health today (Levy \& Marshall, 2004). Faced with such a situation, the high antimicrobial potential of essential oils (EOs), their ability to improve the effectiveness of antibiotics (ABs) and the lack of any apparent emergence of bacterial resistance to them or their components make them valuable subjects of research (Bakkali et al., 2008; Sienkiewicz et al., 2017). In fact, essential oils are made up of many molecules, which make bacteria vulnerable to antibiotics (Sienkiewicz et al., 2017). The occurrence of synergism is thought to be the key to the bioactivity of EOs (Boonyanugomol et al., 2017; Chouhan et al., 2017). Therefore, the association between EOs and ABs has emerged as a novel approach in controlling multidrug-resistant (MDR) strains and modulating the activity of ABs (Boonyanugomol et al. 2017; Chouhan et al., 2017; Boudjedjou et al., 2018, 2019).
Ruta montana is one of the four species of the genus Ruta, from Rutaceae family; grow wild in Algeria (Quézel \& Santa, 1963). All are perennial herbaceous plants with yellow flowers, characterized by a strong, foul-smelling, nauseating odor, due to an essential oil contained in enormous secretory pockets (Hammiche et al., 2013). In folk medicine, R. montana is used for the treatment of persistent cough by fumigation. The infusion or decoction of the aerial parts in milk is used for all problems related to the female genital system such as painful periods and after childbirth. Their decoction in olive oil is used for rheumatism and body aches. Their infusions are used as eye drops for corneal ulcers, as ear drops for otitis and tinnitus, as nasal drops to treat atrophic rhinitis, for fever and vomiting in infants and children (Hammiche et al., 2013).

Previous studies have shown that $R$. montana can be considered as an important source of biologically interesting compounds, namely alkaloids, coumarins, flavonoids, tannins and essential oils (Kambouche et al., 2008; Boutoumi et al., 2009; Belkessame et al., 2011; Bouzidi et al., 2012; Zellagui 
et al., 2012; Hammiche et al., 2013; Ferhat et al., 2014; Khadhri et al., 2014; Hammami et al., 2015; Hazzit et al., 2015; Daoudi et al., 2016; Bennaoum et al., 2017; Fekhar et al., 2017; Benali et al., 2020; Drioiche et al., 2020; Mohammedi et al., 2020), with biological activities including antioxidant (Kambouche et al., 2008; Zellagui et al.,2012; Benali et al., 2020; Mohammedi et al., 2020), antifungal (Hammami et al., 2015; Hazzit et al., 2015; Fekhar et al., 2017; Benali et al., 2020; Drioiche et al., 2020; Mohammedi et al., 2020), insecticidal and larvicidal (Boutoumi et al., 2009; Fekhar et al., 2017).

The chemical composition of Ruta montana essential oils (RMEOs) from various localities and harvested at different seasons have been reported in several papers. The results showed that RMEOs are characterized by the predominance of 2-ketones, such as 2-undecanone and 2-decanone, whereas terpene components were present in lower amounts, with the exception of caryophyllene oxide which occurs as a major component of RMEOs (Bennaoum et al., 2017). The variation in the content of terpene components can be ascribed to many factors, such as the harvesting period (Bennaoum et al., 2017), plant organ (Khadhri et al., 2014), and geographical origin (Mohammedi et al., 2020).

The antibacterial activity of RMEOs seems a bit controversial. Yet, several studies have reported a moderate to the strong antibacterial activity of RMEOs (Belkessame et al., 2011; Zellagui et al., 2012; Hazzit et al., 2015; Daoudi et al., 2016; Fekhar et al., 2017; Benali et al., 2020; Drioiche et al., 2020; Mohammedi et al., 2020). However, to our knowledge, there are no reports on the combination of RMEOs with antibiotics. Hence, this study aimed to investigate the chemical composition and to compare the antibacterial activity of $R$. montana essential oil alone and in combination with some recommended antibiotics against three pathogenic bacteria.

\section{MATERIALS AND METHODS}

\section{Plant Material}

Arial parts of Ruta montana (Clus.) L. were collected in May 2015, during the period of full flowering, from T'kout, department of Batna in Algeria, at 35.0547 (latitude in decimal degrees) and 6.2235 (longitude in decimal degrees). The identification of plant material has been demonstrated according to the flora of Quezel \& Santa (1963). A voucher specimen has been deposited in the Herbarium of our laboratory under the code RUT-001-1-2015. The plant material was cleaned of impurities, dried at room temperature in the dark for two weeks, then cut into small pieces not exceeding $1 \mathrm{~cm}$ and kept in paper bags to be used for the extraction of essential oils.

\section{Extraction and Analysis of the Essential Oil}

The air-dried plant material (150 g) was subjected to steam hydrodistillation for $3 \mathrm{~h}$ using a Clevenger-type apparatus (Clevenger, 1928). The oil obtained was stored in a sealed vial in the dark at $4{ }^{\circ} \mathrm{C}$ until analysis. Quantitative and qualitative analyses of the collected oil were determined by gas chromatography coupled with mass spectrometry (GC/MS). Mass spectra of EO were obtained using a GC focus (Thermo) with BR5-MS column (5\% phenyl methyl siloxane), $30 \mathrm{~m}$ long and $0.32 \mathrm{~mm}$ i.d., with $0.25 \mu \mathrm{m}$ film thickness (Bruker). Coupled to a mass spectrometer (MS) type DSQII (Thermo) with a detector impact of electrons, $70 \mathrm{eV}$. The carrier gas is

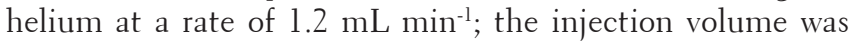
$0.1 \mu \mathrm{L}$; injector split mode 1:100. The initial temperature of the column was kept at $70{ }^{\circ} \mathrm{C}$ for $1 \mathrm{~min}$ and programmed to $300{ }^{\circ} \mathrm{C}$ at a rate of $10^{\circ} \mathrm{C}$. $\mathrm{min}^{-1}$ and kept constant at $300{ }^{\circ} \mathrm{C}$ for $5 \mathrm{~min}$. The mass spectrum of each compound was recorded between 40 and $500 \mathrm{Da}$ (m/z equivalent unit). Identification of compounds was achieved by comparison of their recorded mass spectra with those of a computer library (NIST2008 v2.0/ Xcalibur data system) provided by the instrument software, and of their retention indices with literature data (Adams, 2001). Retention indices (RI) were calculated by the retention times of a series of n-alkanes.

\section{Antibacterial Screening}

The antibacterial activity of $R$. montana $\mathrm{EO}$ was tested against three bacterial strains (Staphylococcus aureus ATCC25923, Pseudomonas aeruginosa ATCC27853, and Escherichia coli ATCC25922) using two different methods: the agar disc diffusion and the Broth micro-dilution methods respectively.

\section{Agar disc diffusion assay}

The agar disc diffusion assay was performed as recommended by the Food and Drug Administration (FDA) and the Clinical and Laboratory Standards Institute (CLSI) (de Sousa Eduardo et al., 2018). Sterile filter discs (6 mm in diameter) impregnated with $10 \mu \mathrm{L} /$ disk of the RMEO were placed onto the Petri dishes containing $20 \mathrm{~mL}$ of Mueller Hinton Agar (MHA) and inoculated with the tested bacteria $\left(10^{8} \mathrm{CFU} \mathrm{mL}^{-1}\right)$. The plates were then incubated at $37^{\circ} \mathrm{C}$ for $24 \mathrm{~h}$. The antibacterial activity was evaluated by measuring the diameter of the inhibition zone around the discs. Standard discs of five conventional antibiotics: gentamycin $10 \mu \mathrm{g}$ disk $^{-1}$, amoxicillin $25 \mu \mathrm{g}$ disk $^{-1}$, cefazolin $30 \mu \mathrm{g}$ disk $^{-1}$, tetracycline $30 \mu \mathrm{g} \mathrm{disk}^{-1}$, and Amoxicillin/Clavulanic Acid (claventin) 20/10 $\mu \mathrm{g} \mathrm{disk}^{-1}$, were used as positive control, whilst discs soaked with $10 \mu \mathrm{Ldimethyl} \mathrm{sulfoxide} \mathrm{(DMSO)} \mathrm{were} \mathrm{used}$ as the negative control (no zone inhibition was observed).

\section{Determination of the MIC and MBC}

The in vitro minimum inhibitory concentration (MIC) and minimum bactericidal concentration (MBC) of RMEO were determined using a microdilution assay as described by de Sousa Eduardo et al. (2018) with modification. The serial two-fold dilutions of the tested EO were prepared in standard sterile 96-well flat bottom microplates and the layout was designed so that each row covered the final dilution of 500 to $3.9 \mu \mathrm{L} \mathrm{mL} \mathrm{m}^{-1}$. One hundred microliters of $\mathrm{MH}$ broth media and $10 \mu \mathrm{L}\left(10^{8} \mathrm{CFU} \mathrm{mL} \mathrm{mL}^{-1}\right)$ of the bacterial culture were added to each well containing $100 \mu \mathrm{L}$ of the serially diluted test 
$\mathrm{EO}$, giving a final concentration of the bacteria in the well of approximately $10^{5} \mathrm{CFU} \mathrm{mL} \mathrm{mL}^{-1}$. After inoculation overnight at $37^{\circ} \mathrm{C}$, the optical density (OD) was measured. The minimal concentration that has OD less than the OD of the control was defined as the MIC. The MBC was determined as the lowest concentration at which $99.9 \%$ of the bacterial population was killed.

\section{Synergistic Interaction}

The combinatory effect of RMEOwith conventional ABs was evaluated using an agar-disc diffusion method as previously described (Moussaoui and Alaoui, 2015). The standard discs of antibiotics were impregnated with $10 \mu \mathrm{L} /$ disc of the RMEO and were put onto the surface of the inoculated MHA. The plates were incubated for $24 \mathrm{~h}$ at $37^{\circ} \mathrm{C}$ after which the inhibition zones were measured. If the value of the inhibition zone of the $\mathrm{EO} /$ $\mathrm{AB}$ combination is significantly higher $(\mathrm{P}<0.05)$ than the sum of the individual values, this is considered to be a synergistic effect, but if they are equal $(\mathrm{P} \geq 0.05)$, then this is considered an additive effect. The antagonistic effect occurs when the values of the inhibition zones of both treatments separately $\mathrm{EO} / \mathrm{AB}$ are significantly greater than the value of their combination (Boudjedjou et al., 2018, 2019).

\section{Statistical Analysis}

All experiments were carried out in triplicate and the data were reported as the mean \pm stander deviation of three samples. Statistical analysis was performed using Statistica 8.0 software, StatSoft Inc., USA (Hill and Lewicki, 2007). Differences were tested for significance by using the one-way ANOVA test $(\mathrm{P}<0.05)$.

\section{RESULTS AND DISCUSSION}

\section{Chemical Composition of R. Montana EO}

The steam-hydrodistillation of R. montana aerial parts yielded $2.5 \%$ of yellowish essential oil with a strong and penetrating odor. This yield was in the same range as those reported in the literature (0.38 - 6.1\%) (Kambouche et al., 2008; Boutoumi et al., 2009; Bouzidi et al., 2012; Zellagui et al., 2012; Ferhat et al., 2014; Khadhri et al., 2014; Hammami et al., 2015; Hazzit et al., 2015; Daoudi et al., 2016; Bennaoum et al., 2017; Fekhar et al., 2017; Mohammedi et al., 2020).

The obtained EO was chemically characterized using GCMS (Table 1, Figure 1). Table 1 depicts the component's identification and their percentages, as well as the RT and RI values, which are listed in order of their elution from the BR5MS capillary column. Thirty-eight components were identified, representing $98.17 \%$ of the total essential oil components. In addition, eleven unidentified compounds were present in the sample, representing $1.7 \%$ (from 0.09 to $0.43 \%$ ) of the total oil. As expected, the aliphatic ketone 2-Undecanone was found to be the major component of RMEO (63.39\%), followed by 2-Nonanone (5.65\%), 2-Acetoxytetradecane (4.94\%),
Table 1: Percentage composition of the essential oil of Ruta montana (Clus.) L.

\begin{tabular}{|c|c|c|c|}
\hline Compounds & $\mathrm{RT}(\mathrm{mn})$ & RI & Percentage (\%) \\
\hline$\beta$-Terpinene & 4.79 & 975 & 0.43 \\
\hline 0-Cymene & 5.70 & 1027 & 0.16 \\
\hline Limonene & 5.78 & 1031 & 0.16 \\
\hline Eucalyptol & 5.83 & 1034 & 0.24 \\
\hline Acetophenone & 6.43 & 1068 & 0.18 \\
\hline 2-Nonanone & 6.88 & 1094 & 5.65 \\
\hline Linalool & 7.00 & 1001 & 0.37 \\
\hline Nonanal & 7.06 & 1104 & 0.24 \\
\hline Camphor & 7.79 & 1149 & 0.19 \\
\hline 1-Nonanol & 8.17 & 1172 & 0.09 \\
\hline Terpinen-4-ol & 8.32 & 1182 & 0.12 \\
\hline 2-Decanone & 8.53 & 1194 & 4.47 \\
\hline 2-Undecanone & 10.25 & 1305 & 63.39 \\
\hline n-Decanoic acid & 11.29 & 1380 & 0.57 \\
\hline 2-Dodecanone & 11.46 & 1392 & 3.35 \\
\hline$\alpha$-Methylbenzylpropanoate & 11.65 & 1413 & 0.23 \\
\hline 2-Acetoxytetradecane & 11.93 & 1433 & 4.94 \\
\hline 2-Nonenone-4 & 12.56 & 1484 & 0.18 \\
\hline$\beta$-Phenylethylisovalerate & 12.68 & 1494 & 0.15 \\
\hline 2-Tridecanone & 12.74 & 1498 & 2.18 \\
\hline 2-Nonen-4-one & 13.18 & 1533 & 2.8 \\
\hline 1-Cyclododecylethanone & 13.33 & 1545 & 0.18 \\
\hline Asarone & 13.49 & 1557 & 0.1 \\
\hline Nerolidol & 13.59 & 1569 & 0.15 \\
\hline Tridecane-2,4-dione & 13.81 & 1582 & 1.4 \\
\hline Caryophyllene oxide & 13.97 & 1601 & 2.34 \\
\hline Cetylglycidyl ether & 14.20 & 1620 & 0.74 \\
\hline Humulene epoxide II & 14.26 & 1626 & 0.16 \\
\hline Apiol & 14.35 & 1632 & 0.34 \\
\hline $\begin{array}{l}\text { 4,4-Dimethyltetracyclo- }(6,3,2,0)(2,5) 0(1,8) \\
\text { tridecan-9-ol }\end{array}$ & 14.57 & 1651 & 0.9 \\
\hline Isoaromadendrene epoxide & 14.93 & 1685 & 0.26 \\
\hline 1-Cyclopropyl-1-dodecanone & 15.86 & 1770 & 0.34 \\
\hline 2-Bromotetradecane & 16.34 & 1815 & 0.11 \\
\hline Hexahydrofarnesyl acetone & 16.67 & 1847 & 0.21 \\
\hline n-Hexadecanoic acid & 17.86 & 1965 & 0.1 \\
\hline Methoxsalen & 18.73 & 2056 & 0.34 \\
\hline$\alpha$-Acetylacetophenone & 20.31 & 2231 & 0.26 \\
\hline Eicosane & 22.51 & 2499 & 0.15 \\
\hline Yield (\%) & & & 2.5 \\
\hline Monoterpene hydrocarbons ( 3 compounds) & & & 0.75 \\
\hline Oxygenated monoterpene ( 6 compounds) & & & 1.25 \\
\hline Oxygenated sesquiterpene (5 compounds) & & & 3.81 \\
\hline Phenylpropenes (2 compounds) & & & 0.44 \\
\hline Ketones (13 compounds) & & & 84.59 \\
\hline Esters ( 3 compounds) & & & 5.32 \\
\hline Others ( 6 compounds) & & & 2.01 \\
\hline Total (38 compounds) & & & 98.17 \\
\hline
\end{tabular}

RT: retention time. RI: Kovats index. The percentages illustrated in bold correspond to the major components of $R$. montana essential oil.

2-Decanone (4.47\%), and 2-Dodecanone (3.35\%). Among the main compounds identified, there is also the sesquiterpene caryophyllene oxide $(2.34 \%)$. This is in agreement with most of the previous literature on the chemical composition of RMEOs confirming the predominance of 2-Undecanone (Kambouche et al., 2008; Boutoumi et al., 2009; Belkessam et al., 2011; Zellagui et al., 2012; Ferhat et al., 2014; Khadhri et al., 2014; Hazzit et al., 2015; Bennaoum et al., 2017; Benali et al., 2020; Drioiche et al., 2020; Mohammedi et al., 2020). Nevertheless, the difference in the percentage of some minor and major compounds could be attributed to the status of the plant 


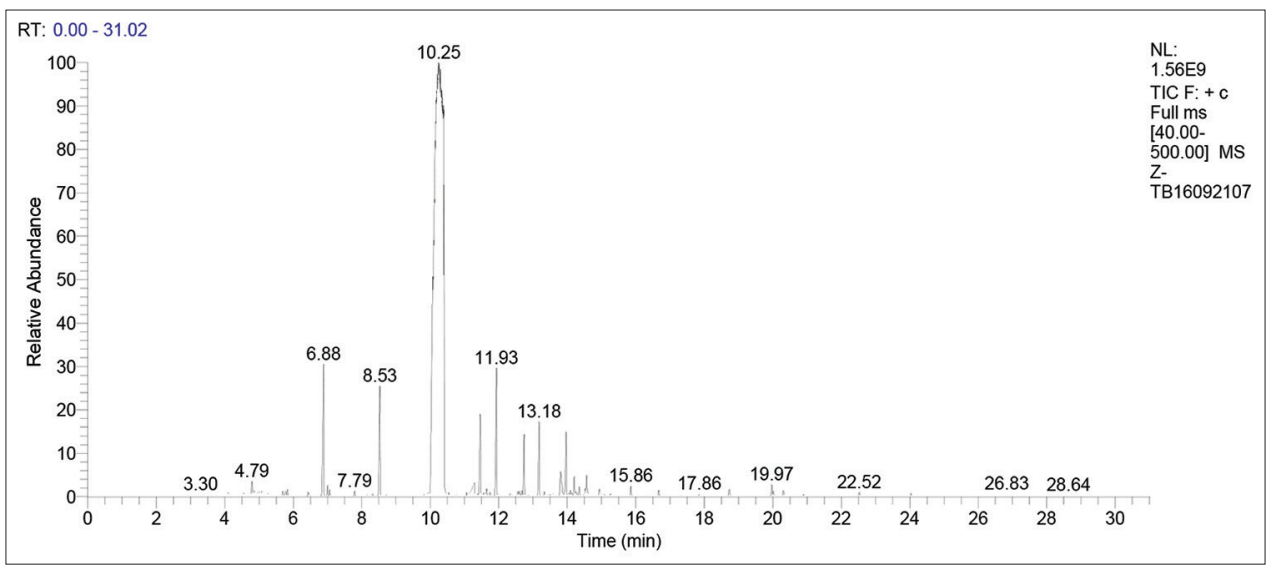

Figure 1: Gas chromatography-mass spectrometry chromatogram of the aerial part essential oil of $R$. montana.

material (dry or fresh), period of harvesting, geographic origin, and the kind of plant material (Kambouche et al., 2008; Boutoumi et al., 2009; Zellagui et al., 2012; Ferhat et al., 2014, Khadhri et al., 2014; Hazzit et al., 2015; Bennaoum et al., 2017; Negri et al., 2020; Mohammedi et al., 2020). Bennaoum et al. (2017), from a study conducted on EOs extracted from 11 samples belonging to three species of the genus Ruta, it has been suggested that the main factors able to influence the chemical composition of RMEO was the harvested period and the geographical origin (Bennaoum et al., 2017). The EOs extracted from plants harvested in spring and winter, as in our case, were characterized by the predominance of ketones, whereas those harvested on summer and autumn seasons were characterized by the predominance of sesquiterpenes and monoterpenes (Bennaoum et al., 2017).

\section{Antibacterial Activity}

The results of the antibacterial activity of RMEO and five standard antibiotics against the three selected pathogenic bacteria are compiled in Table 2. Compared to antibiotics for which all the tested bacteria showed more or less significant sensitivity with the exception of claventin against P. aeruginosa, RMEO was found to be ineffective against all the tested strains. In line with this, the evaluation of MIC and MBC of RMEO (Table 3) showed no or very slight antibacterial activity against E. coli and S. aureus, with MICs of $125 \mu \mathrm{L} / \mathrm{mL}$ and $250 \mu \mathrm{L} / \mathrm{mL}$ for $S$. aureus and E. coli respectively. These results are consistent with some previous studies, which reported that essential oils of Ruta genus displayed no or less antibacterial activity (Merghache et al., 2008; Bnina et al., 2010; Haddouchi et al., 2013). This weak antibacterial activity could be attributed to the high percentage of ketones in the oils (Gibka et al., 2009; Haddouchi et al., 2013). Indeed, the antimicrobial activity of 2-undecanone, the most abundant ketone in this oil, is known to be weak against the bacterial strains (Gibka et al., 2009).

On the other hand, Zellagui et al. (2012) and Bouzidi et al. (2012) reported that the essential oil of $R$. montana has a strong antibacterial activity against all tested bacterial strains (E. coli, S. aureus, P. aeruginosa, Klebsiella pneumoniae, Mycobacterium kansasii, and Mycobacterium vaccae), with an inhibition
Table 2: Inhibition zone diameters $(\mathrm{mm})$ of $\boldsymbol{R}$. montana essential oil and antibiotics.

\begin{tabular}{lccc}
\hline & $\begin{array}{c}\text { E. coli } \\
\text { ATCC25922 }\end{array}$ & $\begin{array}{c}\text { S. aureus } \\
\text { ATCC25923 }\end{array}$ & $\begin{array}{c}\text { P. aeruginosa } \\
\text { ATCC27853 }\end{array}$ \\
\hline RME0 & NI & NI & NI \\
Gentamycin & $18 \pm 1.0$ & $21 \pm 0.5$ & $21.5 \pm 0.5$ \\
Amoxicillin & $8.7 \pm 0.6$ & $15 \pm 1.0$ & $10.7 \pm 0.6$ \\
Cefazolin & $22.7 \pm 0.6$ & $34.7 \pm 0.6$ & $16 \pm 1.0$ \\
Tetracycline & $24 \pm 1.0$ & $26.7 \pm 0.6$ & $23 \pm 1.0$ \\
Claventin & $9.3 \pm 0.6$ & $12 \pm 1.0$ & NI \\
\hline
\end{tabular}

Inhibition zone includes diameter of disk $(6 \mathrm{~mm})$. Values of inhibition diameter are given as mean \pm standard deviation; RMEO: $R$. montana essential oil; NI: No inhibition; ATCC: American type culture collection.

Table 3: In vitro MICs and MBCs $(\mu \mathrm{L} / \mathrm{mL})$ values of RMEO against tested bacteria

\begin{tabular}{lccc}
\hline & $\begin{array}{c}\text { E. coli } \\
\text { ATCC25922 }\end{array}$ & $\begin{array}{c}\text { S. aureus } \\
\text { ATCC25923 }\end{array}$ & $\begin{array}{c}\text { P. aeruginosa } \\
\text { ATCC27853 }\end{array}$ \\
\hline MIC $(\mu \mathrm{L} / \mathrm{mL})$ & 250 & 125 & $>500$ \\
MBC $(\mu \mathrm{L} / \mathrm{mL})$ & 500 & 500 & ND \\
MBC/MIC ratio & 2 & 4 & ND \\
Effect & Bactericidal & Bactericidal & ND \\
\hline
\end{tabular}

MIC: minimum inhibitory concentration; MBC: minimum bactericidal concentration; ND: not determined; ATCC: American type culture collection.

diameter that increases as the concentration of the oil extract increases. This activity appears to be related to the relative amount of hydrocarbon and alcohol terpenes (Haddouchi et al., 2013). It is widely accepted that essential oils rich in aldehydes or phenols have the highest antibacterial activity, followed by those containing alcoholic terpenes. Essential oils containing high levels of ketones or esters have much weaker activity, while those containing terpene hydrocarbons are often inactive (Bassolé \& Juliani, 2012).

\section{Synergistic Interaction}

In order to assess whether or not the addition of essential oils improves the effectiveness of antibiotics, the combined effect of RMEO and five antibiotics recommended against three pathogenic strains were investigated. The results indicated a pronounced antibacterial activity of almost all 


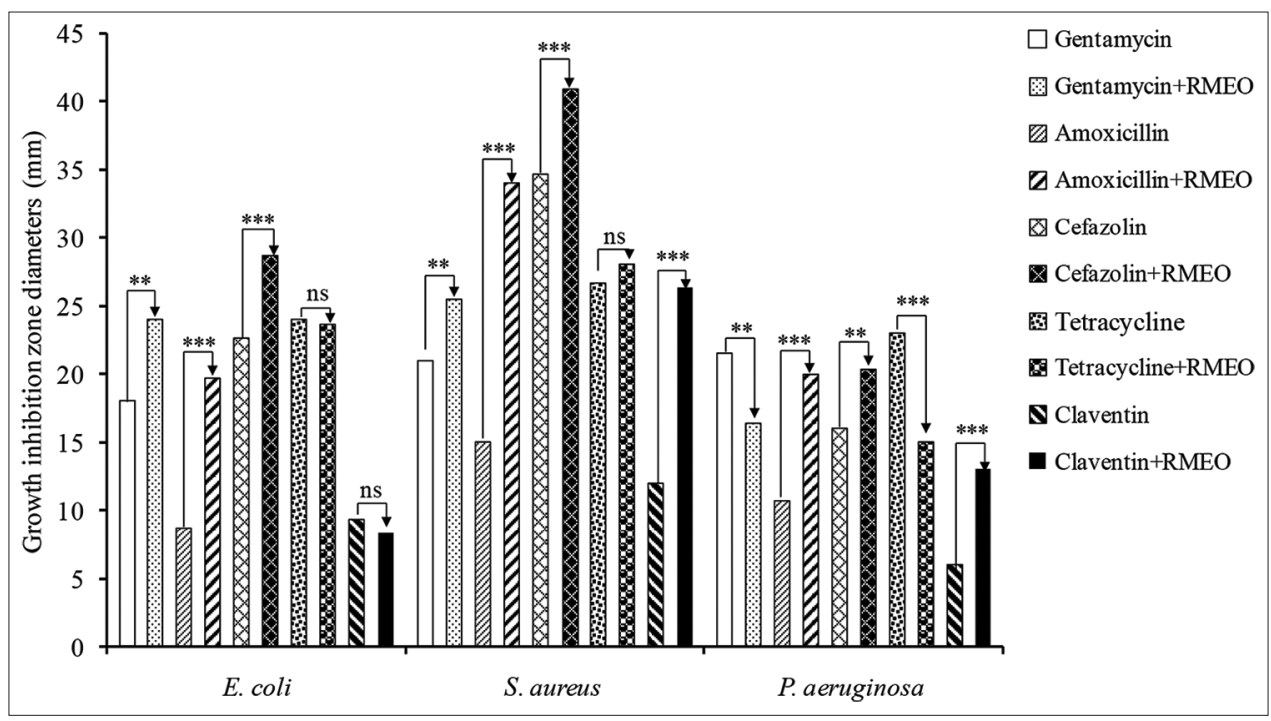

Figure 2: Antibiotic-modulating activity of R. montana essential oil (RMEO) in combination with antibiotics against selected pathogenic strains (E. coli, S. aureus and $\mathrm{P}$. aeruginosa).ns, not significant; *, significant $(\mathrm{P}<0.05)$; ${ }^{* *}$, highly significant $(\mathrm{P}<0.01)$; ${ }^{* *}$; very highly significant $(\mathrm{P}<0.001)$.

Table 4: Inhibition zone diameters ( $\mathrm{mm})$ of $\boldsymbol{R}$. montana essential oil in combination with conventional antibiotics.

\begin{tabular}{|c|c|c|c|}
\hline & $\begin{array}{c}\text { E. coli } \\
\text { ATCC25922 }\end{array}$ & $\begin{array}{c}\text { S. aureus } \\
\text { ATCC25923 }\end{array}$ & $\begin{array}{c}\text { P. aeruginosa } \\
\text { ATCC } 27853\end{array}$ \\
\hline GEN/RMEO & $24 \pm 1.0$ & $25.5 \pm 1.5$ & $16.5 \pm 1.0$ \\
\hline AMX/RMEO & $19.7 \pm 0.6$ & $34 \pm 1.0$ & $20.3 \pm 0.6$ \\
\hline CEF/RMEO & $28.7 \pm 0.6$ & $41 \pm 1.0$ & $21.5 \pm 0.5$ \\
\hline TET/RMEO & $23.7 \pm 0.6$ & $28 \pm 1.0$ & $15 \pm 1.0$ \\
\hline CLA/RMEO & $8.3 \pm 0.6$ & $26.3 \pm 0.6$ & $13 \pm 1.0$ \\
\hline \multicolumn{4}{|l|}{$P$ values } \\
\hline GEN/RMEO & $0.0018^{* *}$ & $0.0079 * *$ & $0.0015^{* *}$ \\
\hline AMX/RMEO & $0.00002^{* * *}$ & $0.00002 * * *$ & $0.00015^{* * *}$ \\
\hline CEF/RMEO & $0.0002 * * *$ & $0.00068 * * *$ & $0.0028 * *$ \\
\hline TET/RMEO & $0.643^{\text {ns }}$ & $0.116^{\mathrm{ns}}$ & $0.0006 * * *$ \\
\hline CLA/RMEO & $0.1^{\text {ns }}$ & $0.000028 * * *$ & $0.00026 * * *$ \\
\hline \multicolumn{4}{|c|}{ Combination effect } \\
\hline GEN/RMEO & Synergistic & Synergistic & Antagonistic \\
\hline AMX/RMEO & Synergistic & Synergistic & Synergistic \\
\hline CEF/RMEO & Synergistic & Synergistic & Synergistic \\
\hline TET/RMEO & Additive & Additive & Antagonistic \\
\hline CLA/RMEO & Additive & Synergistic & Synergistic \\
\hline
\end{tabular}

Values were expressed as mean \pm standard deviation. Ns, not significant; $*$, significant $(P<0.05) ; * *$, highly significant $(P<0.01) ; * * *$, very highly significant $(\mathrm{P}<0.001)$; RME0: R. montana essential oil;

GEN: gentamycin; AMX: amoxicillin; CEF: cefazolin; TET: tetracycline; CLA: claventin; ATCC: American type culture collection.

$\mathrm{ABs} / \mathrm{RMEO}$ combinations against the three tested bacterial strains, even against $P$. aeruginosa (gram-negative) the most resistant strain among the tested ones (Table 4). RMEO showed significant synergistic effects, making bacterial strains more sensitive when combined with gentamycin, amoxicillin, cefazolin, and claventin, as evidenced by the significant increase in the inhibition zone diameters (Figure 2). It should, however, be noted that the GEN/RMEO and TET/RMEO combinations induced antagonistic effects against $P$. aeruginosa.

It is widely accepted that synergy can occur if the components of a mixture affect different targets (Lewis \% Ausubel, 2006;
Wagner and Ulrich Merzenich, 2009). Considering the weak RMEO's antibacterial activity, the synergism observed between RMEO and the different $A B s$ is likely due to the fact that EOs facilitates the penetration of $\mathrm{ABs}$ into the bacterial cells, since the lipophilic nature of oils can causes expansion of the membrane, increased membrane fluidity and permeability (Sienkiewicz et al., 2017). On the other hand, given the great synergistic effect induced by the interaction between RMEO and the $\beta$-lactam antibiotics (amoxicillin, cefazolin, and claventin), which are known to act by inhibiting the synthesis of the peptidoglycan layer of bacterial cell walls (Elander, 2003), it can be also assumed that these ABs facilitates the diffusion of essential oils into the cell.

\section{CONCLUSION}

In the present study, the chemical composition and antimicrobial activity of $R$. montana essential oil alone and in combination with some antibiotics were investigated. The results showed that the combination of R. montana $\mathrm{EO}$ with conventional antibiotics, particularly with amoxicillin and cefazolin induced significant synergistic effects against all pathogenic strains tested. Therefore, the combination of antibiotics and essential oils have the potential to be used as an alternative therapeutic treatment, not only to reduce possible adverse effects and the cost of antibiotic-based treatments but also to prevent the development of bacterial resistance.

\section{ACKNOWLEDGEMENTS}

This work was supported by the Algerian Ministry of Higher Education and Scientific Research and the DGRSDT.

\section{CONFLICT OF INTERSTS}

The authors claim that there is no conflict of interest. 


\section{REFERENCES}

Adams, R.P. (2001). Identification of essential oil components by Gas chromatography/Mass spectroscopy. (3ird ed.).USA: Allured Publishing Corporation

Bakkali, F., Averbeck, S., Averbeck, D., \& Idaomar, M. (2008). Biological effects of essential oils-a review. Food \& Chemical Toxicology, 46 (2), 446-475. https://doi.org/10.1016/j.fct.2007.09.106

Bassolé, I.H.N., \& Juliani, H.R. (2012). Essential oils in combination \& their antimicrobial properties. Molecules, 17(4), 3989-4006. https://doi. org $/ 10.3390 /$ molecules 17043989

Belkassam, A., Zellagui, A., Gherraf, N., Lahouel, M., Rhouati, S. (2011). Abdelwahab, B., Amar, Z., Noureddine, G., Mesbah, L., \& Salah, R. (2011). Essential oil composition of Algerian Ruta montana (Clus.) L. \& its antibacterial effects on microorganisms responsible for respiratory infections. Advances in Natural \& Applied Sciences, 5(3), 264-269.

Benali, T., Habbadi, K., Khabbach, A., Marmouzi, I., Zengin, G., Bouyahya, A., \& Hammani, K. (2020). GC-MS analysis, antioxidant \& antimicrobial activities of Achillea odorata Subsp. pectinata \& Ruta montana essential oils \& their potential use as food preservatives. Foods, 9(5), 668. https://doi.org/10.3390/foods9050668

Bennaoum, Z., Benhassaini, H., Falconieri, D., Piras, A., \& Porcedda, S. (2017). Chemical variability in essential oils from Ruta species among seasons, \& its taxonomic \& ecological significance. Natural Product Research, 31(19), 2329-2334. https://doi.org/10.1080/14786419.20 17.1303692

Bnina, E. B., Hammami, S., Daamii-remadi, M., Jannet, B. H., \& Mighri, Z. (2010). Chemical composition \& antimicrobial effects of Tunisian Ruta chalepensis L. essential oils. Journal de la Société Chimique de Tunisie. 12, 1-9.

Boonyanugomol, W., Kraisriwattana, K., Rukseree, K., Boonsam, K., \& Narachai, P. (2017). In vitro synergistic antibacterial activity of the essential oil from Zingiber cassumunar Roxb against extensively drug-resistant Acinetobacter baumannii strains. Journal of Infection \& Public Health, 10(5), 586-592. https://doi.org/10.1016/j. jiph.2017.01.008

Boudjedjou, L., Ramdani, M., Zeraib, A., Benmeddour, T., \& Fercha, A. (2018). Chemical composition \& antibacterial activity of berries essential oils of Algerian Juniperus thurifera (var. aurasiaca). Pharmaceutical Sciences, 24, 240-245. https://doi.org/10.15171/ PS.2018.35

Boudjedjou, L., Ramdani, M., Zeraib, A., Benmeddour, T., \& Fercha, A. (2019). Chemical composition \& Biological activities of Santolina africana essential oil. Scientific African, 4, e00090. https://doi. org/10.1016/i.sciaf.2019.e00090

Boutoumi, H., Moulay, S., \& Khodja, M. (2009). Essential Oil from Ruta montana L. (Rutaceae): Chemical Composition, Insecticidal \& Larvicidal Activities. Journal of Essential Oil Bearing Plants, 12(6), 714-721. https://doi.org/10.1080/0972060X.2009.10643780

Bouzidi, M.A., Latrèche, A., Attaoui, I., Benabderrahmane, M., Mehdadi, Z., \& Benyahia, M. (2012). Antibacterial effect of the essential oils extracted from Ruta chalepensis L. \& Ruta montana (L.) L. Journal of Life Sciences, 6, 898-902.

Chouhan, S., Sharma, K., \& Guleria, S. (2017). Antimicrobial activity of some essential oils: present status \& future perspectives. Medicines, 4(3), 58. https://doi.org/10.3390/medicines4030058

Clevenger, J. F. (1928). Apparatus for the determination of volatile oil. Journal of the American Pharmaceutical Association, 17(4), 345-349. https://doi.org/10.1002/jps.3080170407

Daoudi, A., Hrouk, H., Belaidi, R., Slimani, I., Ibijbijen, J., \& Nassiri, L. (2016). Valorization of Ruta montana \& Ruta chalepensis: ethnobotanical study, phytochemical screening \& Antibacterial activity. Journal of Materials \& Environmental Science, 7(3), 926-935.

de Sousa Eduardo, L., Farias, T. C., Ferreira, S. B., Ferreira, P. B., Lima, Z. N., \& Ferreira, S. B. (2018). Antibacterial Activity \& Timekill Kinetics of Positive Enantiomer of $\alpha$-pinene against strains of Staphylococcus aureus \& Escherichia coli. Current Topics in Medicinal Chemistry, 18(11), 917-924. https://doi.org/10.2174/156802661866 6180712093914

Drioiche, A., Amine, S., Boutahiri, S., Saidi, S., Ailli, A., Rhafouri, R., Mahjoubi, M., El Hilali, F., Mouradi, A., Eto, B., \& Zair, T. (2020). Antioxidant \& antimicrobial activity of essential oils \& phenolic extracts from the aerial parts of Ruta montana $\mathrm{L}$. of the middle atlas mountains-Morocco. Journal of Essential Oil Bearing Plants, 23(5), 902-917. https://doi.org/10.1080/0972060X.2020.1829995

Elger R. P. (2003). Industrial production of beta-lactam antibiotics. Applied Microbiology \& Biotechnology, 61(5-6), 385-392. https://doi. org/10.1007/s00253-003-1274-y

Fekhar, N., Boutoumi, H., Krea, M., Moulay, S., Drioueche, A., \& Benmaamar, A. (2017). Thionation of essential oils from Algerian Artemisia herba-alba L. \& Ruta montana L.: Impact on their antimicrobial \& insecticidal activities. Chemistry Journal of Moldova, 12(2), 50-57. https://doi.org/10.19261/cjm.2017.410

Ferhat, M., Kabouche, A., \& Kabouche, Z. (2014). Comparative compositions of essential oils of three Ruta species growing in different soils. Journal of Materials \& Environmental Science, 5(3), 735-738.

Gibka, J., Kunicka-Styczyñska, A., \& Gliñski, M. (2009). Antimicrobial activity of Undecan-2-one, Undecan-2-ol \& their derivatives. Journal of Essential Oil Bearing Plants, 12, 605-614. https://doi.org/10.1080 10972060X.2009.10643763

Haddouchi, F., Chaouche, T. M., Zaouali, Y., Ksouri, R., Attou, A., \& Benmansour, A. (2013) Chemical composition \& antimicrobial activity of the essential oils from four Ruta species growing in Algeria. Food Chemistry, 141(1), 253-258. https://doi.org/10.1016/j. foodchem.2013.03.007

Hammami, I., Smaoui, S., Ben Hsouna, A., Hamdi, N., \& Triki, M.A. (2015). Ruta montana L. leaf essential oil \& extracts: Characterization of bioactive compounds \& suppression of crown gall disease. EXCLI Journal, 14, 83-94. https://doi.org/10.17179/excli2014-655

Hammiche, V., \& Azzouz, M. (2013). Les rues: Ethnobotanique, Phytopharmacologie et Toxicité. Phytothérapie, 11, 22-30. https:// doi.org/10.1007/s10298-013-0751-9

Hazzit, M., Benchabane, A., Baaliouamer, A., Alloun, K., \& Kaci, M. (2015). Composition chimique et activité antimicrobienne de l'extrait non volatil et des huiles essentielles de la rue des montagnes (Ruta montana L.). Recherche Agronomique, 27, 118-129.

Hill, T., \& Lewicki, P. (2007). Statistics: Methods Applications, Statsoft, Tulsa, OK, Electronic version is available at: www.statsoft.com textbook/k-nearest-neighbors/.

Kambouche, N., Merah, B., Bellahouel, S., Bouayed, J., Dicko, A., Derdour, A., Younos, C., \& Soulimani, R. (2008). Chemical composition $\&$ antioxidant potential of Ruta montana L. essential oil from Algeria. Journal of Medicinal Food, 11(3), 593-595. https://doi.org/10.1089/ jmf.2007.0515

Khadhri, A., Bouali, I., Belkhir, S., El Mokni, R., Smiti, S., Almeida, C., Nogueira, J.M.F., Eduarda, M., \& Araújo, M. (2014). Chemical variability of two essential oils of Tunisian Rue: Ruta montana \& Ruta chalepensis. Journal of Essential Oil Bearing Plants, 17(3), 445-451. https://doi.org/10.1080/0972060X.2014.914001

Levy, S. B., \& Marshall, B. (2004). Antibacterial resistance worldwide: causes, challenges \& responses. Nature Medicine, 10, S122-S129. https://doi.org/10.1038/nm1145

Lewis, K., \& Ausubel, F. M. (2006). Prospects for plant-derived antibacterials. Nature Biotechnology, 24(12), 1504-1507. https://doi.org/10.1038/ nbt1206-1504

Merghache, S., Hamza, M., Bendahou, M., \& Tabti, B. (2008). Chemical composition \& antimicrobial activity of Ruta chalepensis L. essential oil from Algeria. Asian Journal of Chemistry, 20(4), 2989-2996.

Mohammedi, H., Mecherara-Idjeri, S., \& \& Hassani, A. (2020). Variability in essential oil composition, antioxidant \& antimicrobial activities of Ruta montana L. collected from different geographical regions in Algeria. Journal of Essential Oil Research, 32(1), 88-101. https://doi.org/10.1 080/10412905.2019.1660238

Moussaoui, F., \& Alaoui, T. (2015). Evaluation of antibacterial activity \& synergistic effect between antibiotic \& the essential oils of some medicinal plants. Asian Pacific Journal of Tropical Biomedicine, 6(1), 32-37. https://doi.org/10.1016/j.apjtb.2015.09.024

Negri, L. M., Spontón, E. A., Salgado, O., Sancho, A., \& Denoya, G. I. (2020). Effect of different drying conditions on volatile compounds of Canelo pepper (Drimys winteri). Journal of Phytology, 12, 56-61. https://doi. org/10.25081/jp.2020.v12.6297

Quézel, P., \& Santa, S. (1963). Nouvelle flore de l'Algérie et des régions désertiques méridionales. Centre National de la Recherche Scientifique, Paris.

Sienkiewicz, M., Łysakowska, M., Kowalczyk, E., Szymańska, G., Kochan, E. 
Krukowska, J., Olszewski, J., \& Zielińska-Bliźniewska, H. (2017). The ability of selected plant essential oils to enhance the action of recommended antibiotics against pathogenic wound bacteria. Burns, 43(2), 310-317. https://doi.org/10.1016/j.burns.2016.08.032

Wagner, H., \& Ulrich Merzenich, G. (2009). Synergy research: approaching a new generation of phytopharmaceuticals. Phytomedicine, 16(2-3),
97-110. https://doi.org10.1016/j.phymed.2008.12.018

Zellagui, A., Belkassam, A., Belaidi, A., \& Gherraf, N. (2012). Environmental impact on the Chemical composition \& yield of essential oils of Algerian Ruta montana (Clus.) L. \& their antioxidant \& antibacterial activities. Advances in Environmental Biology, 6(10), 2684-2688. 